\title{
Portinari e Bonadei
}

\author{
Nelson Aguilar
}

Duas teses de mestrado concluídas em 1977 vêm à luz somente neste momento: Portinari, pintor social 'de Annateresa Fabris, publicada na coleção "Estudos” da Editora Perspectiva e Aldo Bonadei: o percurso de um pintor de Lisbeth Rebollo Gonçalves, editada na série "Debates" da mesma editora.

Um índice importante para localizar sua procedência provém das dedicatórias: ambas trazem o nome da prof- Gilda Rocha de Mello e Souza, uma das fundadoras da história universitária da arte paulista ao lado do prof. Flávio Motta.

Os dois orientadores do olhar têm algo em comum que mereceria ser estudado com o devido cuidado: produziram textos relativamente curtos e densos, cuja capacidade de penetração desafia o pensamento analítico do leitor. Todos os que vivemos sob sua égide tentávamos imitar a desenvoltura de suas descobertas, o alcance de suas intuições, a pertinência de suas aproximações e, enfim, a sublimidade interpretativa. Quando uma análise de quadro tentada por nós, alunos, conseguia bom resultado, considerávamo-nos próximos de nossos mestres. A ilusão no entanto durava até a aula seguinte, ou até a publicação de novo texto por parte de um deles. Aí tudo se derretia, voltávamos às respectivas mediocridades, aprendizes de feiticeiros desenxabidos.

Candido Portinari desempenha um papel ambivalente na história da arte brasileira: sua grande reputação caminha em razão inversa do estudo interpretativo de sua obra. Annateresa fez o gesto inaugural, elaborando um ensaio de longo fôlego sobre o artista, pairando acima das monografias encomiásticas e dos textos polêmicos. Mesmo o livro de Antônio Bento, publicado depois da tese de mestrado (Rio de Janeiro, Leo Christiano Editorial Ltda., 1980), pertence ao primeiro gênero. A situação dos estudos portinarianos desde a dissertação de Annateresa ate hoje se modificou apenas do ponto de vista da catalogação graças ao Projeto Portinari, desenvolvido no Rio de Janeiro, por uma equipe liderada pelo filho do artista, João Cândido. Quanto à pesquisa filológica, muito resta por fazer, mas o início da tarefa está delineado por Annateresa.

O livro se divide em quatro partes: a nota biográfica, o “problema Portinari", a trajetória artística e o pintor social.

$\mathrm{Na}$ nota biográfica, a ensaísta semeia pontos de teor coisal (Sachgehalt), para empregar a noção benjaminiana que coloca o leitor a caminho da verdade artística. Assim, quando Portinari parte para o Rio de Janeiro, em 1918, a fim de estudar pintura, aguarda no purgatório do Liceu de Artes e Ofícios, instituição mais condizente à situação social de filho de colonos italianos, a senha para ingressar na Escola Nacional de BelasArtes, trampolim para projetos mais ambiciosos. Em 1924, já aluno da Escola Nacional, infringe a lei enviando ao Salão Nacional quadro com temática pouco platônica, "Baile na roça". Reproduz-se o episódio da "Fosca" de Carlos Gomes: a ópera, mal recebida, torna o compositor cauteloso. Mais adiante, a autora explora o veio aurífero da crítica de Mário de Andrade para pontuar a carreira de Portinari. Aqui, ocorrem lacunas importantes. Textos básicos são negligenciados. Não falo do ensaio então inédito sobre o
NELSON AGUILAR é professor de História da Arte no Departamento de História do IFCH/Unicamp e crítico de arte da Folha de S. Paulo.

Aldo Bonadei: o Dercurso de um pintor, He Lisbeth Rebollo Gonçalves, co-ediçăo Fapesp-Edusp-Perspectiva, $218 \mathrm{pp}$.

Portinari, pintor social, de Annateresa Fabris, co-ediçăo Secretaria de Estado da Cultura-Edusp-Perspectiva, 150 pp. 

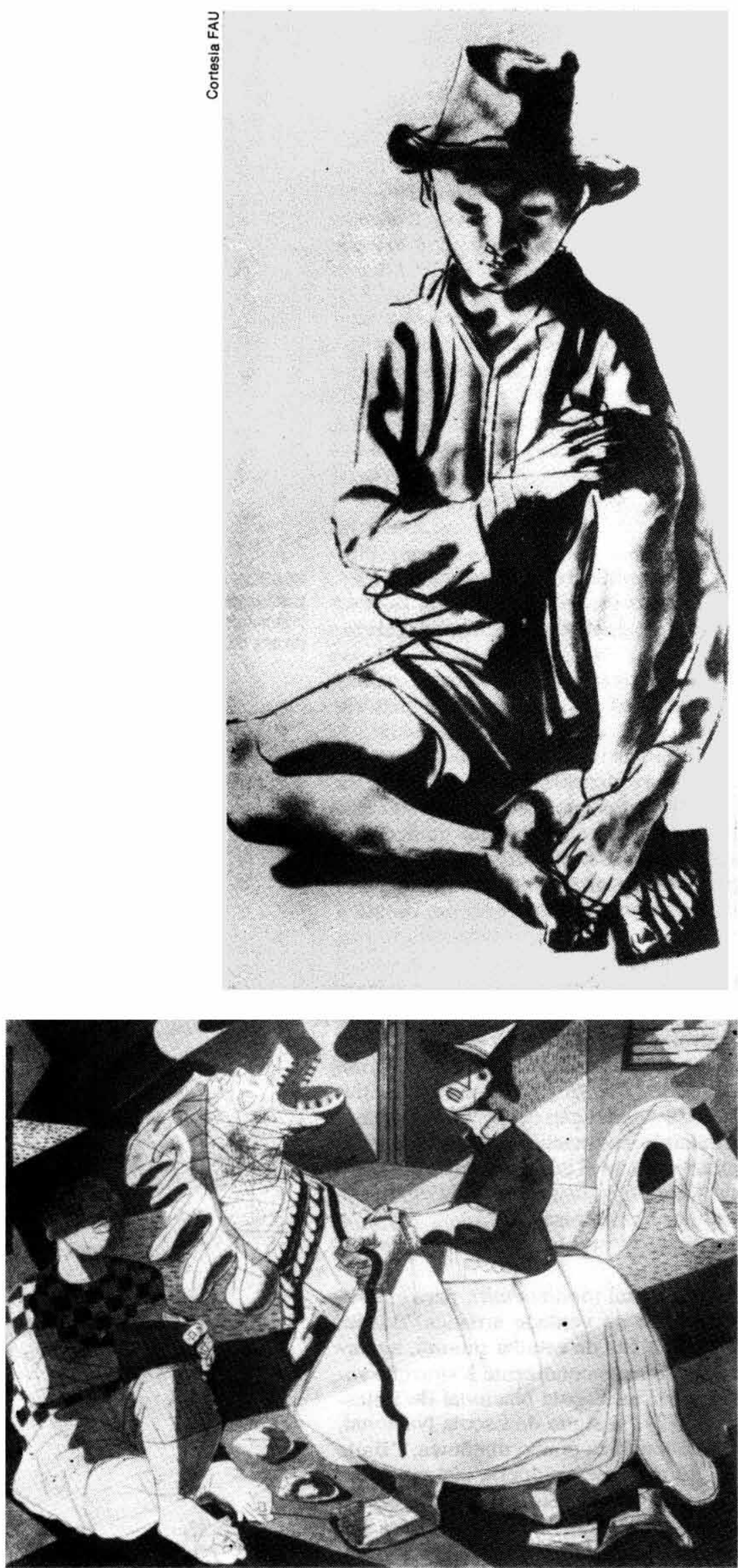

pintor de Brodósqui que a Revista do Patrimônio Histórico e Artístico Nacional iria editar em 1984, ao qual a pesquisadora não teve acesso. Mas artigos importantes como o do "Mundo musical", "Esboço para um Portinari em castelhano" (Folha da Manhã, $26 / 10 / 1944$ ), resumo do mencionado acima, ficaram de fora, além das contribuiçōes ao suplemento em rotogravura do Estado de $S$. Paulo.

Se Annateresa tivesse seguido a pista do artigo publicado na rubrica de "Mundo musical", depararia com um tópico que possui para a crítica cultural brasileira importância semelhante a do caso Nietzsche/Wagner para a congênere alemã. $O$ desentendimento entre Mário de Andrade e Portinari fez com que este sustasse a publicação da monografia feita pelo autor de Macunatma para a Argentina. O pintor, promovido a herói nacional nos idos de 40, não suportou a imagem de si, demasiado humana, que o escritor the oferecia.

Seguindo a esteira aberta por Paulo Mendes de Almeida em "De Anita ao museu", a autora dedica capítulo ao "problema Portinari". Mostra que mesmo historiadores de arte do porte de Frederico Morais e Aracy Amaral foram vítimas de fase negativa na história da recepção do mestre de Brodósqui. Como exemplo oposto, o militante Gerson Knispel comparece com o conhecido discurso humanitário stalinista, enaltecendo a capacidade do artista de "fazer progredir e aperfeiçoar as conquistas estéticas em função de nosso tempo glorificando a figura humana". Sob sugestão da

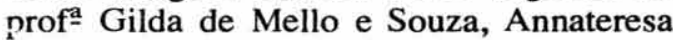
fornece a exata dimensão mítica de Portinari, comparando seu funeral ao de Di Cavalcanti. Lá, homenagens oficiais, políticos e grande massa popular, aqui, "duzentas pessoas no velório, cinqüenta no enterro, a presença de uma única autoridade".

Escrever sobre pintura é tarefa arriscada, no limite do possível, "§ preciso fazer falar o que gostaria de permanecer mudo", o que envolve teorias complexas onde o único meio de iniciação reside no contínuo confronto com a figura. No livro em questão, a falta de um apoio iconográfico se faz sentir duramente. Não obstante as reproduções sofríveis de segunda mão (provenientes da obra de Antônio Bento), em preto e branco, sem nenhum dado técnico que norteie o leitor, a maior parte dos quadros analisados não estão disponíveis ("O homem dos sorvetes", 1934, "Baiana com crianças", 1933, "Marias", 1936, os três painéis da Feira Mundial de Nova York, 1939 e outros tantos). Os livros de arte, especialmente 
quando são co-editados com a Editora da Universidade de São Paulo (Edusp) e a Secretaria de Estado da Cultura de São Paulo, não deveriam receber acabamento gráfico tão medíocre.

O grande mérito do livro está no olhar honesto, desarmado, com que a pesquisadora aborda a obra do grande artista. Portinari não seria um dos grandes pintores do Brasil sem uma maestria na formação do espaço. Algumas obras-chave são tratadas através de análise muito figurativa, como "São João" (1934), na opinião de Mário de Andrade e outros, uma das maiores obras do artista. Nota a ensaísta que "a captação da realidade popular é feita em termos nitidamente geométricos que a concreticidade física das figuras não perturba de modo algum: triângulos (grupos de três mulheres no primeiro plano; mulheres de lata na cabeça e homem carregando madeira), verticais (troncos de palmeiras, mastros, vários grupos de figuras) em contraposição a linhas curvas (paisagem do fundo)". A proliferação de cilindros e blocos geométricos solicita a obra de outro artista que talvez ajude a elucidar o intuito do brasileiro, a saber, o russo Casimir Malévitch, na fase cubo-futurista. Lá também os trabalhos e os dias do homem rural passam por um tratamento esférico, volúmico, que encontrariam um desenvolvimento no Fernard Leger de após Primeira Guerra Mundial e em outros pintores como o belga Constant Permeke. A natureza exuberante impõe a marca da fecundidade: o grande seio que nutre a humanidade. $\mathrm{O}$ formigamento das formas em "São João" passa por esta utopia alucinante. $\mathrm{O}$ resultado é obtido pela multiplicação de um grafema em forma de foice, isto é, de uma linha reta associada a uma curva que se projeta no espaço pictural. A superfície se torna túmida pela contraposição sistemática das direçōes lineares e curvilíneas. As observações sobre a tensão dinâmica que percorre os painéis da Fundação Hispânica da Biblioteca do Congresso de Washington (1941) têm sua origem na afinidade profunda de Annateresa com o futurismo italiano.

A eleição que os intelectuais cariocas fizeram de Portinari como pintor-protótipo do modernismo brasileiro teve razão estratégica, lembra a ensaísta. Os passadistas criticavam na pintura moderna brasileira a ausência de métier, isto $\varepsilon$, de domínio do desenho, no sentido acadêmico do termo. Anita, Tarsila, Di Cavalcanti, Cícero Dias, entre outros, estavam desqualificados para assumir o papel de pintor moderno, pois entre os prerequisitos constava desenho acadêmico. A intelligentzia nativa, em clave de "retorno à ordem", ansiava por um Picasso, capaz de fazer frente às reviravoltas da moda, produzindo se preciso retratos "horrivelmente semelhantes", como comentara com tanto propósito Cézanne as tentativas de certos contemporâneos. Mas já havia o modelo de pintor moderno que sabia desenhar academicamente na praça: Lasar Segall. Portinari retomaria com mais afinco e sem sotaque nos anos 30 a fase brasileira que o artista lituano construíra na década anterior.

O livro toma o aspecto de um vitral composto pela crítica de arte da melhor qualidade e, por vezes, a intuição de um comentador é confirmada por outra de proveniência completamente diferente. Ruben Navarra, um dos grandes nomes da crítica brasileira dos anos 40, observa os "motivos que recordam longinquamente o tema gráfico do papel cortado" utilizado em "Guernica" de Picasso e assimilado por Portinari. O critico francês contemporâneo J. L. Ferrier cauciona o juízo de Navarra: “ 'Guernica' é preta como os cabeçalhos dos jornais da época que dizem ao homem da rua - preto sobre branco - sua terrível atualidade. É preta e branca como as fotos de imprensa enviadas da Espanha por belinógrafo, cuja trama grosseira que vos fere o olhar fala de furor an-



Na outra página, ao alto, "Menino de Brodowski", desenho a óleo e "Carnaval", têmpera; acima, "São Pedro e o galo", bleo sobre tela - obras de Portinari

Dezembro 

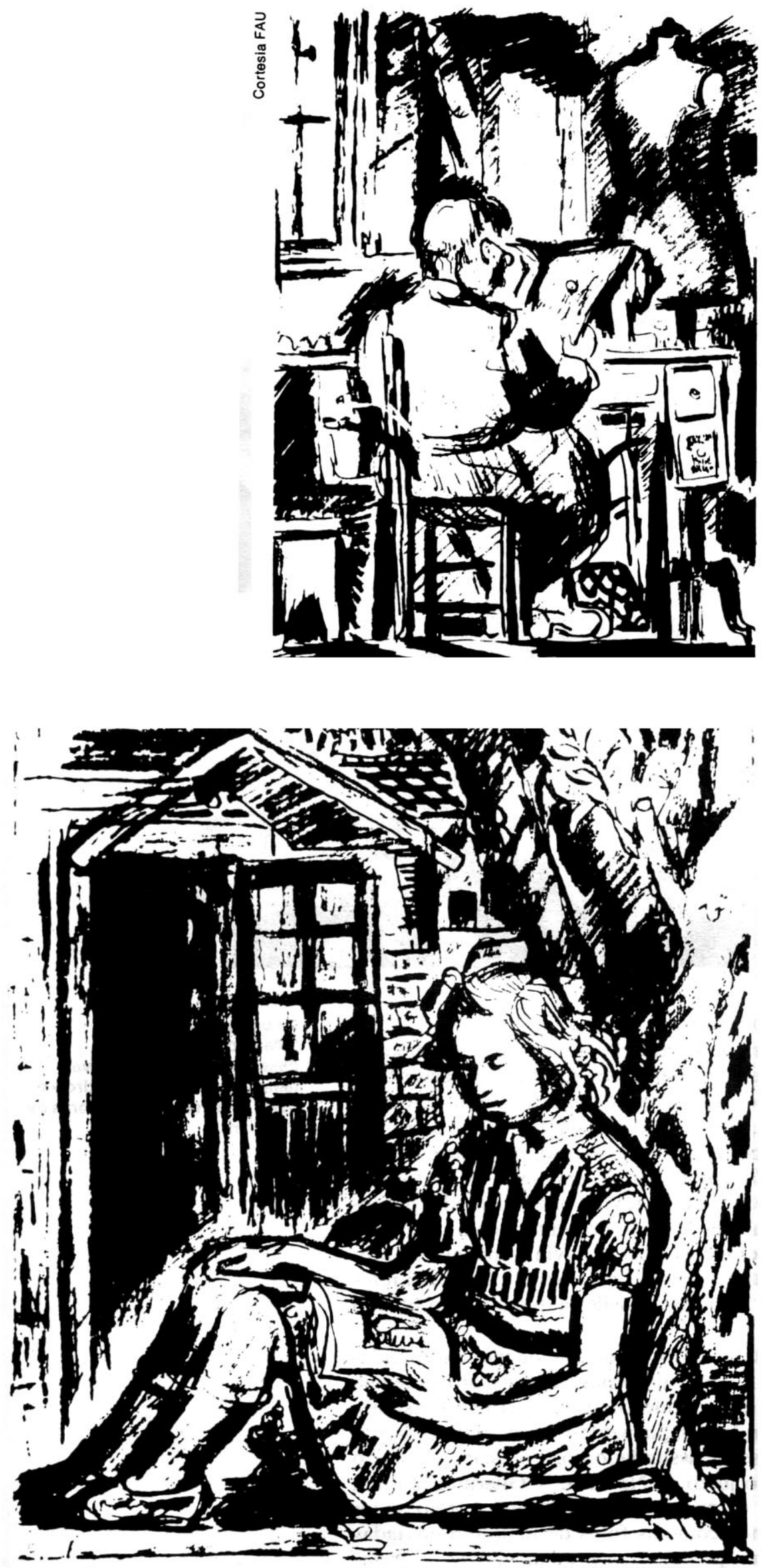

tes mesmo que o olho tenha captado sua imagem". Essas homologias formais enriquecem constantemente o livro de Annateresa.

$\mathrm{Na}$ última parte do ensaio, alvo visado desde o início pela autora, é narrada a edificação do pintor social. As matrizes congêneres à ação do pintor brasileiro são localizadas, a fim de melhor caracterizar sua singularidade: o muralismo mexicano e o realismo norte-americano. Nem as rajadas de metralhadora de Siqueiros tentando alvejar Trotski, nem o olhar perdido de Henry Fonda nas Vinhas da Ira de John Ford parecem fornecer os ingredientes para a compreensão da obra de Candido Portinari. "Nada ê mais difícil aprender que o saber usar livremente o nacional", afirmou Holderlin numa célebre carta. Isso acontece no período em que o pintor articula o árduo diálogo com o próprio que não dura mais que dez anos (1934-44). Basta olhar para a "Colona" (1935) da coleção Mário de Andrade. A protagonista fere os limites da tela por sua escala gigantesca. Tudo se apequena a seu redor. A trindade mulher-casamorro causa uma inquietude, acentuada pela densidade do vermelho que caminha para o azul. A disposição da colona lembra a de uma parturiente, elevada a um grau cósmico.

De 1945 para frente, sua obra passa a ter um interesse sobretudo iconográfico. Um estudo promissor seria o de pesquisar os móveis da crise criativa e existencial que arremessa o artista de uma pintura vigorosa, épica para um estilo mais decorativo. $\mathrm{O}$ livro de Annateresa se encerra neste ponto. $O$ ensaio mais instigante, que ajudaria a elucidar o Portinari "pós-social", é o de Flávio Motta, "Trabalho de um pintor Portinari", publicado na Revista de Historia, vol. XLIV, no 90, ano XXIII, abril-junho de 1972 (no livro de Annateresa, a indicação bibliográfica está incorreta). Flávio realiza sua análise por empatia, fala "com" Portinari e não "sobre" Portinari. Uma das contribuições definitivas de seu ensaio é a articulação entre a pintura e os poemas do muralista. No final de sua vida, o artista perde o poder de sentir a resistência do mundo, vê "sua obra como pura exterioridade". É exatamente o que se depreende de uma obra como "Ceia sagrada" (1960): um exercício virtuosístico que apresenta um pintor que não está mais presente. $O$ desespero de manter a qualquer custo o vínculo com a figuração subentendido ao que é mais exterior à pintura, a saber, a posição político-partidária, torna o verdadeiro pintor um ser "sobressalente", sozinho para si 


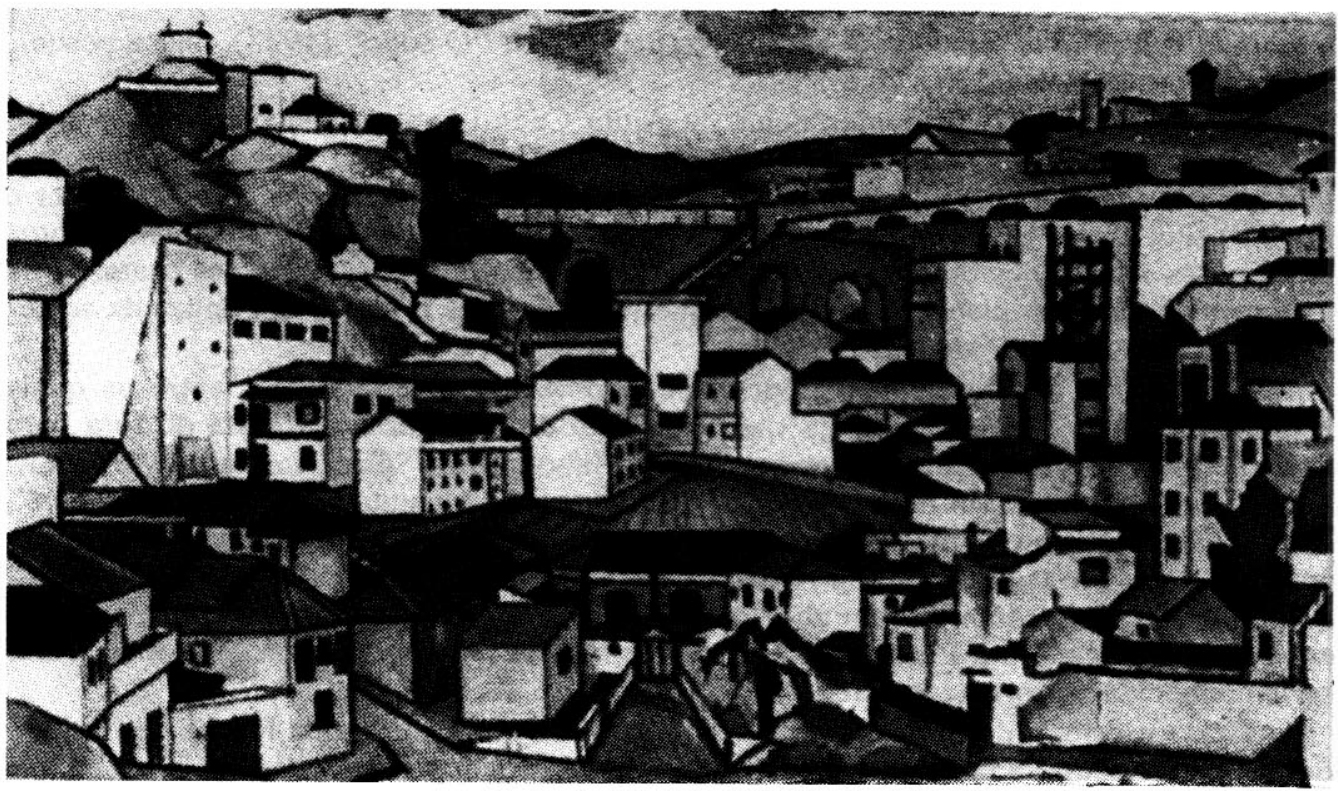

próprio. Neste sentido, o texto de Flávio, que acompanhou os últimos anos do artista, possui um tom elegíaco ao contar a história do "homem que propiciou encontros em sua obra e dela se ausentou".

O livro de Lisbeth sobre Bonadei se notabiliza pela precisão documental, raras vezes atingida no domínio da historiografia artística nacional, e por isso mesmo suas informações foram rapinadas pelo oportunismo editorial, quando a tese se encontrava mimeografada. A prática da pirataria no setor chega a ser natural.

A solução encontrada para a ilustração, embora ainda pobre, representa um avanço em relação ao "Portinari". Quarenta e cinco pequenas reproduções em cores constituem um resumo significativo do corpus bonadeiano, além de documentação iconográfica, em preto e branco, abrangendo fotografias do artista em várias situações, páginas de reflexões anotadas em caderno, desenhos, esquemas gráficos, etc. Infelizmente todas as obras mencionadas no texto não se encontram no corpus e não existe nenhum reenvio no texto ao índice ilustrativo.

Como em todo trabalho consciencioso, até as notas de rodapé são importantes. Numa delas, aprende-se que o primeiro historiador de arte a interpretar o decênio $35-45$ como “período de consolidação da arte moderna brasileira, em São Paulo”, foi Lourival Gomes Machado, em artigo publicado na Folha da Manhã, de 25/10/44. Esta descoberta foi sistematizada pelo prof. Antonio Candido no prefácio ao livro de Paulo Duarte, "Mário de Andrade por ele mesmo", quando caracteriza os anos 30 como o tempo de "rotinização do Modernismo".

Lisbeth acompanha a formação artística de Bonadei. Os primórdios não se diferem de outros pintores paulistanos, filhos de imigrantes italianos. Estuda no Liceu de Artes e Ofícios, procura as aulas de Pedro Alexandrino, passa um ano letivo na Academia de Belas-Artes de Florença (1930-31), ajuda a família na oficina de costura, realizando modelos e desenhos para bordados. É interessante operar a comparação com Portinari, que parte da zona rural à Capital Federal, imbuído de toda a esperança da família, numa supra-determinação destinal. Bonadei, pelo contrário, amadurece lentamente, amparado pela solidariedade pequeno-burguesa do clã urbano. Mesmo participando do grupo da Família Artística com Volpi, Rebolo, Pennacchi, Martins, Rizzotti, Graciano e Zanini, não se distingue dos colegas. "Falta a coragem de errar”, diagnostica Mário de Andrade.

$\mathrm{Na}$ década de 40, Bonadei desperta e conquista sua autonomia. A fase das "Impressões Musicais" revela um ousado experimentalista. O pintor tenta realizar em suas obras a música. Talvez por partir de compositores que trabalham dentro do sistema tonal (Beethoven, Paganini), produz seqüências sucessivas de elementos crescentes. Porêm, o espantoso é que esses acordes picturais vêm do próprio suporte da tela, sem localização determinada. Bonadei já trata o espaço da tela como superfície criativa. Existe
Acima, "Casario", bleo sobre tela de 1966 de Aldo Bonadei; na outra página, duas gravuras do mesmo artista 
um clima surrealista, semelhante ao do óleo de Tarsila, "O sono" (1928), mas a pesquisa formal predomina sobre a figuração.

Em 1944, assistindo as conferências de Anita Cabral sobre a psicologia da gestalt, tenta compreender a pintura a partir dos postulados da teoria da forma. Daqui vem a tentação de Lisbeth de tornar sua a fascinação do pintor pelas teorias de Wertheimer e de Arnheim. Emprega-as como metodologia para a análise dos quadros. Nos momentos de crise, as faculdades de ciências humanas tentam se atrelar às de ciências exatas. Que melhor aval para um historiador de arte, que navega sobre as perigosas águas da subjetividade, que o de um cientista?

Seria esquecer as liçōes dos próprios fundadores da arte moderna, entre os quais Malévitch e Klee. Malévitch nega que uma obra de arte possa ser vista de fora para dentro, como produto a ser submetido a leis de laboratório. "Cada forma é livre e individual. Cada forma é um mundo." Nos "Elementos fundamentais da teoria da forma", Klee parece ter a premonição do que virá a ser a Gestalttheorie, operando a distinção entre Gestalt, que significa forma, estrutura e Gestaltung, formação. "A teoria da Gestaltung se preocupa com os caminhos que conduzem à Gestalt. É a teoria da forma mas enquanto sinalizadora do caminho que conduz até ela." Sem essa precisão, toda a arte seria conhecida aprioristicamente.

O físico e crítico de arte Mário Schenberg, que ao lado de Gilda Rocha de Mello e Souza e Flávio Motta constituem o âmago do olhar artístico em São Paulo - sem os três a vida das formas entre os anos 60 e 80 teria sido insossa -, é mais reservado quanto ao alcance da gestalt no campo das artes plásticas. A apresentação que faz à exposição de homenagem a Bonadei em junho e julho de 1978 no Museu de Arte de São Paulo, posterior portanto à tese de Lisbeth, indica um caminho promissor aos estudiosos do pintor.

Mário Schenberg localiza o ponto fulcral da pintura de Bonadei ao mencionar seu embate entre o lirismo e sua vontade de contenção. É uma luta dramática que atravessa a obra do artista. Há uma afirmação da forma em seu fazer, semelhante a que acompanha a produção de Campigli, Rosai, Sironi, o Carrà pós-futurista. A temporalidade implicada é incidente, opondo-se a Volpi que se manifesta sempre em posição de gerúndio, processual. O próprio uso de técnicas diferentes - o óleo por Bonadei e a têmpera por Volpi - obedece à concepção rítmica de cada um.

No livro, teria sido importante documentar suas telas costuradas e confrontá-las a experiências de artistas que intervieram na epiderme de seus trabalhos como Burri e Fontana. Por que Lisbeth não incluiu o conto policial do artista "A mancha verde - um crime do abstrato" escrito em colaboração com Camila Cerqueira César e apresentado pela ensaísta na revista Discurso no 7 do Departamento de Filosofia da USP? O detetive Caporal Miranda, irmão gêmeo do inspetor Leite criado por Luís Lopes Coelho e alter ego do pintor, descobre nas telas de Sardo uma imagem recorrente que o conduz à elucidação do crime. Mas o grande protagonista da história tachista de Bonadei é a cor. Como Portinari, o artista paulistano fez poesias. Pelo exemplo da única transcrita, teria valido a pena editar outras pela limpidez do tom lírico, além do evidente interesse heurístico.

Observando as reproduçōes da obra do artista, um outro fato salta à vista: a influência das bienais em seu trabalho. A presença das premiaçōes se reflete na orientação. No princípio da década de 50, sopra o vento da abstração, sobretudo a vertente representada por Alfred Manessier, Jean Bazaine, Charles Lapicque e Maurice Esteve. Bonadei quebra a figuração e se serve de linhas abstrato-concretas, linhas que gradualmente ocultam a figuração, como elementos constitutivos do todo. A figuração só acontece no segundo plano, pois se acha destruída pelo labirinto linear que, ao invadir a obra em todas as direções, exprime estas direções de maneira mais universal, mais formal, porque mais simples, sem aceitar o excesso da realidade sensível, tendendo a uma forma que conserva os vestígios do ponto de partida. Toda a parte orgânica do que é objetivo desaparece e cede lugar ao que se poderia considerar formal-objetivo, não mais orgânico objetivo.

A arte de Bonadei procura a arquitetura do mundo sensível. Neste sentido, seria interessante seguir a sugestão do crítico Theon Spanudis - parece que é essa a pesquisa atual de Lisbeth - e palmilhar a ascendência do universalismo construtivo de Joaquin Torres-Garcia sobre pintores como Aldo Bonadei e Arnaldo Ferrari.

Os livros de Annateresa e Lisbeth contribuem para desvendar um painel que se poderia intitular o afresco carcamano, marcando a origem de uma brasilidade feita pela diferença. 